\title{
Maternal Antenatal Corticosteroid Treatment and Childhood Mental and Behavioral Disorders
}

\section{Sjölander, Arvid}

2020-10-20

Sjölander , A , Kaprio , J \& Latvala , A 2020 , ' Maternal Antenatal Corticosteroid Treatment and Childhood Mental and Behavioral Disorders ', JAMA : The Journal of the American Medical Association, vol. 324 , no. 15 , pp. 1570-1570 . https://doi.org/10.1001/jama.2020.15452

http://hdl.handle.net/10138/328227

https://doi.org/10.1001/jama.2020.15452

unspecified

acceptedVersion

Downloaded from Helda, University of Helsinki institutional repository.

This is an electronic reprint of the original article.

This reprint may differ from the original in pagination and typographic detail.

Please cite the original version. 


\section{LE Sjolander 20-14746 edited}

$7 / 11 / 20$

Your letter has been edited for conciseness and for consistency with JAMA style; please do not replace deleted material or add new material except where requested. To revise the document, please accept the changes in a clean copy; make any additional changes and respond to questions, including confirmation of financial disclosures, directly on the copy using Track Changes. Please do not remove the manuscript number or date at the top. 
Group Title: Maternal antenatal corticosteroid treatment and childhood mental and behavioral disorders

To the Editor:

Dr Räikkönen and colleagues ${ }^{1}$ examined the association between maternal antenatal corticosteroid treatment and mental and behavioral disorders in children. We are concerned that there may be an important statistical error in the analysis.

An essential element of the authors' conclusions was their statistical analysis of "within-sibpair comparison,s, in which they estimated differences in cumulative incidence rates and hazards ratios. The authors claimed that their analysis automatically adjusted for unmeasured familial confounding. 
However, this claim is incorrect for the estimated hazard ratios, since these compared siblings between families with treatment and families without treatment, rather than between treated and untreated siblings within families, as would be expected in a within-sibpair comparison.

Specifically, the authors' hazards ratios compared treated siblings from treatment discordant pairs (numerator) to siblings from pairs in which both siblings were untreated (denominator). This comparison is non-standard, and there is no reason why it would adjust for unmeasured familial confounding.

Consider the following example. Suppose that women with low socioeconomic status are at a higher risk of preterm delivery and hence also at higher probability of receiving the treatment. Suppose also that children who are born to mothers with low socioeconomic status are at a higher risk of mental disorders. Then siblings from pairs in which one sibling is treated will more often have mothers with low socioeconomic status, and will thus more often have mental disorders, than siblings from pairs in which both siblings are untreated. In the presence of such familial confounding, the hazard ratios estimated by Räikkönen and colleagues will be greater than 1 even in the complete absence of a treatment effect. In contrast, by comparing siblings from the same family, a correct within-sibpair comparison would, to a large extent, adjust for socioeconomic status, since this factor is fairly constant within families across time.

The within-sibling comparison is a powerful epidemiological design that, if used correctly, may adjust for a large set of unmeasured confounders. We thus encourage Räikkönen and colleagues to provide a correct within-sibpair analysis of their data, as in Sjölander et $\mathrm{al}^{2-4}$ or Allison. ${ }^{5}$ 
Arvid Sjölander

Department of Medical Epidemiology and Biostatistics

Karolinska Institute

Stockholm, Sweden

Jaakko Kaprio, MD, PhD

Institute for Molecular Medicine Finland

University of Helsinki

Helsinki, Finland

Antti Latvala, $\mathrm{PhD}$

Institute of Criminology and Legal Policy

University of Helsinki

Helsinki, Finland

Corresponding Author: Arvid Sjölander, Department of Medical Epidemiology and

Biostatistics, Karolinska Institute, Nobels väg 12A, 17177 Stockholm, Sweden

(arvid.sjolander@ki.se).

We have received the Disclosure of Conflicts of Interest from all authors. Please confirm that you have disclosed all potential conflicts of interest. Our policy requires that all authors disclose all potential conflicts of interest, including specific financial interests and relationships and affiliations relevant to the subject of their manuscript within the past 3 years and for the foreseeable future (eg, employment, consultancies, honoraria, stock ownership or options, expert testimony, grants or patents received or pending, royalties). For example, authors of a letter about hypertension should report all financial relationships they have with all manufacturers of products used in the management of hypertension, not only those relationships with companies whose specific products are mentioned in the manuscript. If you are uncertain about what constitutes a relevant financial interest or relationship, please ask. 


\section{Conflict of Interest Disclosures: None reported.}

1. Räikkönen K, Gissler M, Kajantie E. Associations between maternal antenatal corticosteroid treatment and mental and behavioral disorders in children. JAMA. 2020;323(19):1924-1933. doi: 10.1001/jama.2020.3937

2. Sjölander A, Johansson AL, Lundholm C, Altman D, Almqvist C, Pawitan Y. Analysis of 1: 1 matched cohort studies and twin studies, with binary exposures and binary outcomes. Statistical Science. 2012:395-411. doi: 10.1214/12-STS390

3. Sjölander A, Lichtenstein P, Larsson H, Pawitan Y. Between-within models for survival analysis. Statistics in Medicine. 2013;32(18):3067-3076. doi: 10.1002/sim.5767

4. Sjölander A, Greenland S. Ignoring the matching variables in cohort studies-when is it valid and why? Statistics in Medicine. 2013;32(27):4696-4708. doi: 10.1002/sim.5879

5. Allison, PD. Fixed effects regression models (Vol. 160). Thousand Oaks, CA: SAGE publications; 2009. 